\title{
Cultural Values as a Basis for Well-Being: the Logic of the Relationship and Importance of the Institute of Expert Examination Interpretation
}

\author{
E.A. Royzen ${ }^{\mathrm{a}}$, D.A.Myachin ${ }^{\mathrm{a}}$, A.N. Pershikov ${ }^{\mathrm{b} *}$ \\ * Corresponding author: A.N. Pershikov, regionoved@mail.ru \\ ${ }^{a}$ Saint-Petersburg Branch after V.B. Bobkov of Russian Customs Academy, Str. Sofiyskaya, 52a, St. Petersburg, 192241 , \\ Russia,Email royzenkat@gmail.com,89218779666 \\ ${ }^{b}$ National Research Tomsk Polytechnic University, Av. Lenine, 30, Tomsk. 634034, Russia
}

\begin{abstract}
http://dx.doi.org/10.15405/epsbs.2016.02.8

The article reveals the logic of the relationship of the well-being concept with cultural values. The authors show that a man in his being and understanding of the well-being has been formed by external factors, the most important of which is the state. They examine mechanisms of the concept of the well-being formation through cultural values adopted in the current society. The formation mechanism of cultural values assessment and the significance of the interpretation of the institute of expert examination are shown. The problems of cultural values assessment in the modern Russian expert examination system have been laid out.
\end{abstract}

(C) 2016 Published by Future Academy www.FutureAcademy.org.uk

Keywords: Well-being; cultural values; assessment; expert examination; social adaptation.

\section{Introduction}

The concept of the well-being seems to be so obvious at first sight that the thought that it may be in the center of the disputes is surprising. However, the question of the well-being has occupied thinkers since ancient times. In the definition dictionary by S. I. Ozhegov the term prosperous is defined as 'rich and successful'. Similar definitions in modern dictionaries of the Russian language quite a lot, and as a rule, they explain this term through the concept of a quiet life without misfortune, but with welfare, success, prosperity, happiness. Most of these definitions is not deprived of the synonymity, the absence of the reference to gender and type, which the concept applies to, i.e. they are not the definitions essentially. Other definitions seem to be disputable, if we 
eISSN: 2357-1330

Selection \& Peer-review under responsibility of the Conference Organization Committee

are examining them a little deeper. In this regard, we believe it is necessary to refer to the founder of Logic, some principles of whose logical system although have been challenged over time, in some of its clusters they are still relevant. Basic terms and principles, in particular we are interested in identifying the concepts that are the foundation of all the scientific definitions used in our time.

\section{Review of related research}

In the work of 'Nicomachean Ethics' Aristotle opposes to Socrates in the reasoning of the welfare and well-being, and tries to define the notion of the well-being through the perfect goal. Any our actions are aimed at achieving a certain goal. But quite often an achieved goal represents an intermediate result that is necessary to achieve another, but a higher goal. The good will be the objective itself, and not as sub-goals. Etymological feature of the word well-being is that it contains the concept of an activity 'eypraxia', and in Russian it is the similar situation: 'personal gains'. It is no coincidence that Aristotle defines it as 'the activity of the soul in accordance with the virtue', because the basis of the act is a conscious choice determined by reasonable motives, morals, goals. Aristotle's passage about the role of the state as the measure of benefit has become of an exceptional interest for us. Politics as a science of the state determines to what extent and what skills and sciences are required for the state, following the laws of which leads each individual citizen and the whole nation to the highest the well-being. In the presence of the same circumstances, different people show different reactions, for example, one becomes a coward, the other - a masculine person. What does this type of reaction depend on? According to Aristotle, this reaction depends on what was mastered in man from its childhood.

The viewpoint of the human being's image over the centuries has undergone significant changes. This issue may be a separate study from the point of view of the continuity and logic of the development of this idea. In our article we are not going to focus on this continuity, but only outline the specific direction of our indicated ideas.

Continuing the logic of Aristotle, in the eighteenth century, de Lamar makes human happiness the object of policy ('Treatise on the police', 1705). De Lamar argues that the state must not just rule people or a mass of people living together, but the whole society. Society and people as social beings, individuals, are strong in all their social relations and that is now the true object of the police' (Fuko M, 1988)

In the nineteenth century, the discovery of the unconscious, Marxist economic theory, the nature of power - all of these areas of the Western thought only further indicate that the concept of well-being is formed by something external in relation to a man, i.e. the image of a parent, by the power, structure. In the twentieth century, Michel Foucault says that all our actions are the implementation of some existing currently accepted historical and political rationality associated, in our time, with two correlated factors: an increasingly growing individualization of society and the consolidation of individuals into some integrity.

Summarizing our arguments, we will not be original if we say that a man in his being and understanding of the well-being has evolved by external factors, but nevertheless, we emphasize the idea, as it is the starting point for us. 
http://dx.doi.org/10.15405/epsbs.2016.02.8

eISSN: 2357-1330 / Corresponding Author: A.N.Pershikov,Email: regionoved@mail.ru

Selection and peer-review under responsibility of the Organizing Committee of the conference

The next step of our reasoning is to refer to an issue of values. Axiology is a branch of Philosophy on the theory of values, in the forefront of which are such names as G. Zimmel, W. Windelband, G. Rickert, T. Parsons, W. Dilthey, etc. The common aspects for these researchers are the difference of societies according to their values; the definition of values as a way of describing societies in which they are adopted as some independent variables. The reasoning of Georg Zimmel for us is of exceptional interest, since in the field of the issues it involves the concept of cultural values. The wellknown cases of lack of human socialization (Teraline people) point to the social nature of a language and the need for social interaction for the development of a person in the usual sense. Man, absorbed some patterns of the reality interpretation and realizing this interpretation in his respective practice, would be seen as quite a mature for the current society. This raises the question of how these patterns are transmitted. According to Zimmel, the quintessential values of the society are the cultural values. And mastering them a person from a 'wild culture' becomes a full member of this society. Thus, applying this idea to the question of the well-being, the essence of which, as we concluded above, the ruling elite determines, we conclude that the patterns of the social adaptation responsible for the complementary nature of the society and society as a whole may not quite completely specified by the authority, but are manageable. Moreover, the cultural values of this logic are management tools of the well-being as a valuable point of the society. In our opinion, this idea is the defining quality of the notion of the well-being, it largely reflects the subjective content of a private nature of well-beings, which nevertheless have similar common features.

\section{Models introduction}

This is the theoretical side of the concept of the well-being, as we understand it in its qualitative characteristics. But instead proposed a quantitative component, we would like to reveal the practical side of the relationship between cultural values and the well-being. The first thought on this subject declared by the majority of scientists working in this area is a variety of definitions of cultural value, their diversity and associated with it a gap of cultural definitions and legal practice. Our society owns a certain amount of items, which contain the whole essence of driving forces and movements of our society. The management effectiveness requires that values are not replicated, and otherwise the original loses its value. One could argue that in the era of the mass reproduction is reversed, but it is only the outer side. Indeed, the reproduction of a great work can hang on the wall of the toilet, devaluing the original by its presence in this space, but it's hard to imagine that the original itself has been in this place. However, in practice, it never happens. This is the exception, the distortion, in which no one is interested. The society accumulates cultural values, places them in museums, galleries and a variety of stores. The depreciation of values means the destruction of society, loss of power to control its members, the breakdown in the accepted interpretations of reality, changes of practical actions headed by former values, in a word, a revolution. An important place in the preservation of their values from their destruction is the institute of interpretation, the function of which is to determine what is valuable and what is not, where the original is, and where a fake is. This function is performed by the institute of expert examination, actually existing and aiming, on a superficial level of understanding, to evaluate items (the original version) and to assess their value, usually for utilitarian purposes related to 
eISSN: 2357-1330

Selection \& Peer-review under responsibility of the Conference Organization Committee

the movement of cultural values across state borders. However, utilitarian purposes, as we consider, are just a reflection of the essence of deeper processes.

The authorities' attitudes to cultural values of their people are the expression of the degree of their consistency in questions of management and real power. The institute of expert examination is applied as a filter of the truth and value of cultural objects.

According to the Ministry of Culture of Russia dated 25.12.2014 № 2448, the examination shall be performed by individuals who have been certified and authorized by the state to conduct examinations. The level of the Russian experts' professionalism is regarded as a very high one, and at the same time, the experts recognize the fact of the bias of expert assessments. This bias is associated, as indicated by many sources, with the complexity and the impossibility of regulating the liability of an expert. Article 58 of the Federal Law on export and import of cultural values indicates that the expert, who has given a knowingly false expert evidence, shall be criminally liable in accordance with the applicable law. In practice, the presence of criminal intent can be proved almost impossible, the inadvertency of the error, on the other hand, relieves the expert from his liability. As a result, the impunity of the expert is one of the major sources of corruption and violations in the sphere of the protection of cultural heritage of the country.

The regulation of certain items, which should be currently contained in the expert assessment, is an attempt to formalize the expert examination process. Where is the opportunity of ignoring the human factor in the evaluation of objects, it is a sphere of determining the value of cultural values. At present there are several methods of valuing them, which experts use as a guide: the method by A. Rozhdestvensky and the method by I. Zharov, as well as guidelines of the Standardization System of the Chamber of Commerce and Industry of the Russian Federation (A. G. Gagarin, E. V. Tikhomirova, E. P. Dill, N. E. Karpova, based on the method of the analytic hierarchy process by Thomas Saati. Although the reason for the establishment of these techniques was the need, to some extent, for formalizing the expert assessment, these methods themselves are conceptually different. For example, the method by A. Rozhdestvensky is based on the production of a number of similar items on the basis of the most revealing and significant parameters, i.e. the determination of the plurality whose elements meet the certain conditions and are subject to the certain laws. In fact, all the items of this plurality are a collection of separate parameters combining 4-5 items in the collection. The change each of them affects the final result of the evaluation, and therefore, it is possible to determine the 'cost' of each parameter and the degree of its change depending on a given 'step' of a change of a given parameter, and as a result, to know the value of the item of evaluation, depending on the specified parameters in the context of a given plurality. The method by I. Zharov is based on the consideration of a cultural value according to its separate parts, in case this separation is legitimate (for example, the icon and its frame, the blade and its handle) and on the definition of increasing and decreasing criteria (in total 21) in the assessment items. The cost of cultural values in this method is expressed in the gold equivalent [5]. Perhaps the evaluation results on these and other techniques will be more or less similar, but we have not found the evidence for this assumption in monographs, theses and other research works. 
http://dx.doi.org/10.15405/epsbs.2016.02.8

eISSN: 2357-1330 / Corresponding Author: A.N. Pershikov,Email: regionoved@mail.ru

Selection and peer-review under responsibility of the Organizing Committee of the conference

\section{Conclusion}

Thus, the most important social institution, the examination of cultural values, that rules the society, and which is formally deprived of the responsibility for the outcomes of its activities. On the one hand, this type of depravation discredits it, and on the other hand, it reflects, as in a mirror, undesirable processes of the government.

\section{Acknowledgements}

We thank the anonymous referees for their constructive and useful comments on the paper.

\section{References}

Definitio dictionary by Ozhegov online. Available: http://slovarozhegova.ru/

Aristotle 'Nicomachea ethics'. Available: http://www.lib.ru/POEEAST/ARISTOTEL/nikomah.txt

Fuko M. (1988) The Political technology of individuals. Available:

http://www.gumer.info/bibliotek Buks/Culture/Fuko intel power/Fuko 19.php

G. Zimmel (1996) Favorites. Philosophy of culture. M: Lawyer. 671p. Available: http://www.countries.ru/library/texts/zimmelosc.htm

Ruskultekspertiza: National research Institute of examination and evaluation of objects of cultural history. Available: http://rusculturexpertiza.ru 